\title{
Comparison Study of Image Performance with Contrast Agent Contents for Brain Magnetic Resonance Imaging
}

\author{
Youngjin Lee ${ }^{1}$, Min Hyeok Choi ${ }^{1}$, Hee Jin Goh $^{2}$, and Dong-Kyoon Han ${ }^{1 *}$ \\ ${ }^{1}$ Department of Radiological Science, 553, Sanseong-daero, Sujeong-gu, Seongnam-si, Gyeonggi-do, Republic of Korea \\ ${ }^{2}$ Department of Radiology, Asan Medical Center, 88 Olympic-ro 43-gil, Songpa-gu, Seoul, Republic of Korea
}

(Received 22 February 2016, Received in final form 30 March 2016, Accepted 30 March 2016)

\begin{abstract}
The purpose of study was to evaluate SNR and CNR with different contrast agent contents $(1.0 \mathrm{mmol} / \mathrm{mL}$ gadobutrol and $0.5 \mathrm{mmol} / \mathrm{mL}$ gadoterate meglumine) for spin echo (SE) and 3-dimension contrast-enhanced fast field echo (3D CE-FFE) pulse sequences. In this study, we compared the SNR and the CNR between 0.5 $\mathrm{mmol} / \mathrm{mL}$ gadoterate meglumine and $1.0 \mathrm{mmol} / \mathrm{mL}$ gadobutrol according to the concentration of contrast agent in brain MRI. When we compared between SE and 3D CE-FFE pulse sequences, the higher SNR and CNR using 3D CE-FFE pulse sequence can be acquire regardless of contrast agent contents. Also, a statistically significant difference was found for SNR and CNR between all protocols. In conclusion, our results demonstrated that the SNR and CNR have not risen proportionately with contrast agent contents. We hope that these results presented in this paper will contribute to decide contrast agent contents for brain MRI.
\end{abstract}

Keywords : magnetic resonance imaging, quantitative image analysis, MR-angiography (MRA)

\section{Introduction}

The occurrence of the brain metastases, which are the most common type of brain cancer, increase in the following order from lung cancer (18-64\%), via breast cancer $(2-21 \%)$ and melanoma (4-16\%), to colon cancer $(2-11 \%)$. Thus, the importance of early diagnosis for brain cancer is growing bigger [1-3].

Imaging devices for brain cancer consisted of conventional X-ray, computed tomography (CT), positron emission tomography (PET), and magnetic resonance imaging (MRI). Among these imaging devices, MRI is most commonly used in the field of the medical imaging because there is no radiation exposure and excellent tissue contrast resolution can be acquired $[4,5]$. The accuracy of $\mathrm{T}_{2}$ weighted imaging $\left(\mathrm{T}_{2} \mathrm{WI}\right)$ is better than that of the dual energy CT (DECT), which has been used to distinguish between bone and tissue in the head, for the brain cancer imaging [6]. Also, $\mathrm{T}_{2} \mathrm{WI}$ can be improved contrast-tonoise ratio (CNR) by using water (or cerebral spinal fluid) suppression technique $[7,8]$.

The contrast agent for MRI is a very important para-

CThe Korean Magnetics Society. All rights reserved.

*Corresponding author: Tel: +82-31-740-7462

Fax: +82-31-740-7351, e-mail: handk@eulji.ac.kr meter for the definite distinction between normal and lesion tissue. The contrast agent is expected to help in the early detection of diseases because the signal-to-noise ratio (SNR) between normal and lesion tissue can be improved [9]. In brain MRI, the contrast of brain parenchyma using contrast agent is dependent on $T_{1}$ relaxation effect by gadolinium (Gd) contents. There are many methods to improve $T_{1}$ relaxation effect such as increasing main magnetic field, coil sensitivity, and amount of contrast agent per unit area. However, these methods may increase total scan time and the risk of nephrogenic systemic fibrosis (NSF). Recently, many studies have been conducted the effectness of contrast agent between $1.0 \mathrm{mmol} / \mathrm{mL}$ gadobutrol and $0.5 \mathrm{mmol} / \mathrm{mL}$ gadoterate meglumine. According to the previous studies, $1.0 \mathrm{mmol} /$ $\mathrm{mL}$ gadobutrol has high SNR and more useful detection of diseases than $0.5 \mathrm{mmol} / \mathrm{mL}$ gadoterate meglumine in spite of interruption by blood brain barrier (BBB) [10].

In this study, we compared signal intensity $(\mathrm{Si})$ and contrast between $0.5 \mathrm{mmol} / \mathrm{mL}$ gadoterate meglumine and $1.0 \mathrm{mmol} / \mathrm{mL}$ gadobutrol according to the concentration of contrast agent in brain. In addition, we compared between spin echo (SE), which is the most commonly used in the MRI imaging based on the detection of spin with 90 and 180 degree radiofrequency pulse, and 3dimension contrast-enhanced fast field echo (3D CE-FFE) 
pulse sequences.

\section{Materials and Methods}

\subsection{Subjects and methods of study}

Lung cancer is one of the most major cancers in the field of medicine. We acquired MRI imaging for lung cancer patients starting from March to July. Total patients were 35 numbers (man: 26, woman: 9) and mean age of the patients was 68 years. Table 1 shows the list of the lung cancer patient characteristics.

We compared contrast difference according to the $\mathrm{Gd}$ contents using $0.5 \mathrm{mmol} / \mathrm{mL}$ gadoterate meglumine and $1.0 \mathrm{mmol} / \mathrm{mL}$ gadobutrol. Each contrast agent is applied to $\mathrm{SE}$ and 3D CE-FFE pulse sequences. To evaluate image performance, we measured the SNR and CNR with different contrast agent contents. Before the experiments, we have assumed that contrast agent with high contents is useful than low contents. Contrast agents may be administered by injection into the orally or blood stream, depending on the subject condition. A major factor influencing the enhancement of lesion is its vascularity relative to that of brain parenchyma. In this study, we injected contrast agent in the brain parenchyma using $10-20 \mathrm{~mL}$ of mixture with normal saline and each contrast agent based on the patient pain. We used $0.2 \mathrm{cc} / \mathrm{kg}$ and $0.1 \mathrm{cc} / \mathrm{kg}$ using 0.5 $\mathrm{mmol} / \mathrm{mL}$ gadoterate meglumine and $1.0 \mathrm{mmol} / \mathrm{mL}$ gadobutrol, respectively.

\subsection{System and image parameters}

To acquire images, we used 3.0 T MRI system (Achieva, Philips, Netherlands) and 6 cannel head coil (SENSE, Philips, Netherlands) (Fig. 1). Table 2 shows the used parameters using SE and 3D CE-FFE pulse sequences.

\subsection{Evaluation of image performance}

The data were measured on the white matter of brain

Table 1. Patient characteristics according to the gender and age.

\begin{tabular}{cccc}
\hline \hline \multirow{3}{*}{ Gender } & Division & Number & Percent (\%) \\
\cline { 2 - 4 } & Man & 26 & 74.2 \\
& Woman & 9 & 25.8 \\
\cline { 2 - 4 } Age & Total & 35 & 100 \\
\hline \multirow{7}{*}{} & Under 50 & 1 & 2.8 \\
& $50-59$ & 5 & 14.3 \\
& $60-69$ & 13 & 37.2 \\
& $70-79$ & 14 & 40 \\
& Over 80 & 2 & 5.7 \\
\hline & Total & 35 & 100 \\
\hline
\end{tabular}

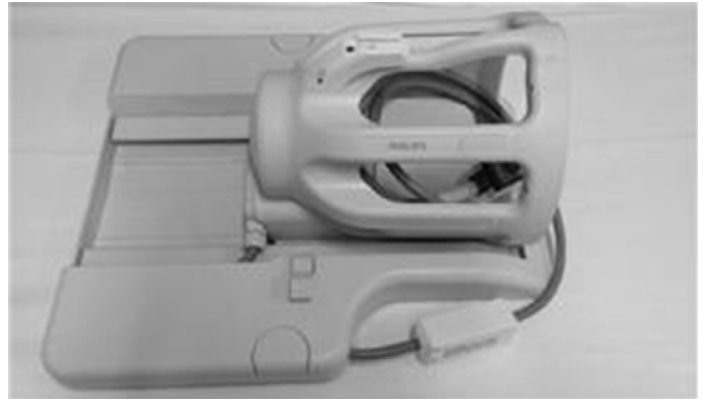

Fig. 1. The photo of 6 channel SENSE head coil.

Table 2. Parameters according to the imaging method.

\begin{tabular}{ccc}
\hline \hline & SE & 3D CE-FFE \\
\hline Scan time & $3 \mathrm{~min} 41 \mathrm{sec}$ & $5 \mathrm{~min} 56 \mathrm{sec}$ \\
Matrix size & $256 \times 256$ & $224 \times 224$ \\
Field of view (FOV) & $230 \times 230 \mathrm{~mm}^{2}$ & $224 \times 224 \mathrm{~mm}^{2}$ \\
Slice thickness & $5 \mathrm{~mm}$ & $\cdot$ \\
Slice gap & $2 \mathrm{~mm}$ & $\cdot$ \\
Slice number & 20 & $\cdot$ \\
Voxel size & $\cdot$ & $1 \times 1 \times 1 \mathrm{~mm}^{3}$ \\
TR/TE & $427 \mathrm{msec} / 10 \mathrm{msec}$ & $9.9 \mathrm{msec} / 4.6 \mathrm{msec}^{2}$ \\
NEX & 1 & 1 \\
Flip angle & $\cdot$ & 8 \\
TFE factor & $\cdot$ & 224 \\
\hline
\end{tabular}

parenchyma, gray matter, and basal ganglion using ROIs of $35.7 \mathrm{~mm}$ diameter. The background was measured using four ROIs of $175.1 \mathrm{~mm}$. Figs. 2 and 3 show the ROI setting using SE and 3D CE-FFE pulse sequence, respectively. The evaluated SNR and CNR were calculated as follows:

$$
\begin{aligned}
& \mathrm{SNR}=\frac{S_{i}}{\sigma_{\text {background }}} \times 100, \\
& \mathrm{CNR}=\frac{S_{i}-S_{s}}{\sigma_{\text {background }}} \times 100,
\end{aligned}
$$

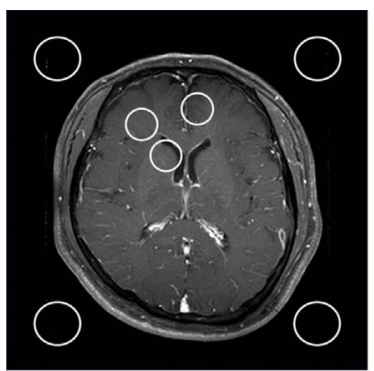

(a)

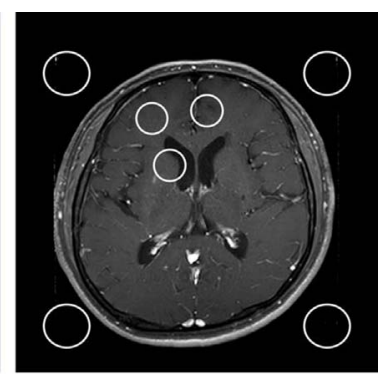

(b)
Fig. 2. ROI measurement setting of $\mathrm{SE}$ pulse sequence using (a) $0.5 \mathrm{mmol} / \mathrm{mL}$ gadoterate meglumine and (b) $1.0 \mathrm{mmol} / \mathrm{mL}$ gadobutrol. 


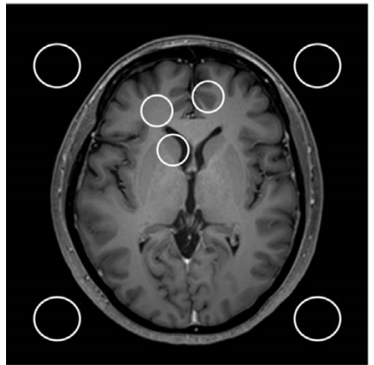

(a)

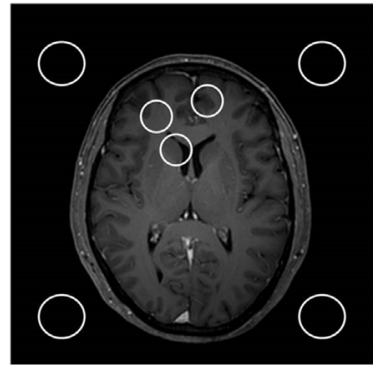

(b)
Fig. 3. ROI measurement setting of 3D CE-FFE pulse sequence (a) $0.5 \mathrm{mmol} / \mathrm{mL}$ gadoterate meglumine and (b) 1.0 $\mathrm{mmol} / \mathrm{mL}$ gadobutrol.

where $\sigma_{\text {background }}$ is the standard deviation and $\mathrm{S}_{\mathrm{s}}$ is the signal intensity of surrounding tissue [11].

We compared SNR and CNR for each contrast agent content and pulse sequence using independent samples Ttest. P-value less than 0.05 was considered to indicate statistical significance.

\section{Results and Discussion}

The brain MRI images of high SNR and CNR have excellent accuracy for clinical imaging. For this reason, the use of contrast agent has facilitated the realization of high quality MRI systems. However, few side effects had been reported with $\mathrm{Gd}$ contrast agent, which is most commonly used in the field of MRI imaging. A disease called NSF, which was first recognized in 1997, was reported to have developed in patients with impaired renal function who had received one of the MRI contrast agents in common use [12]. Thus, the contrast agent should be used with caution because of the side effects in MRI. In previous, many studies have been conducted as improvement methods for SNR and CNR in brain parenchyma. The SNR and CNR with a 3.0 T MRI system were higher than that with a 1.5 T MRI system $[13,14]$. In this study, two contrast agents $(0.5 \mathrm{mmol} / \mathrm{mL}$ gadoterate meglumine and $1.0 \mathrm{mmol} / \mathrm{mL}$ gadobutrol) were considered as MRI system, and the SNR and CNR of each pulse sequence were compared.

Fig. 4 shows the measured SNR of white matter, gray matter, and basal ganglion with respect to the pulse sequences and contrast agent contents. Fig. 5 shows the measured CNR between gray matter and basal ganglion and between white matter and basal ganglion with respect to the pulse sequences and contrast agent contents.

In SE pulse sequence, the measured SNR using 0.5 $\mathrm{mmol} / \mathrm{mL}$ gadoterate meglumine of white matter, gray matter, and basal ganglion was $115.8 \pm 49.4,135.3 \pm 54.4$,
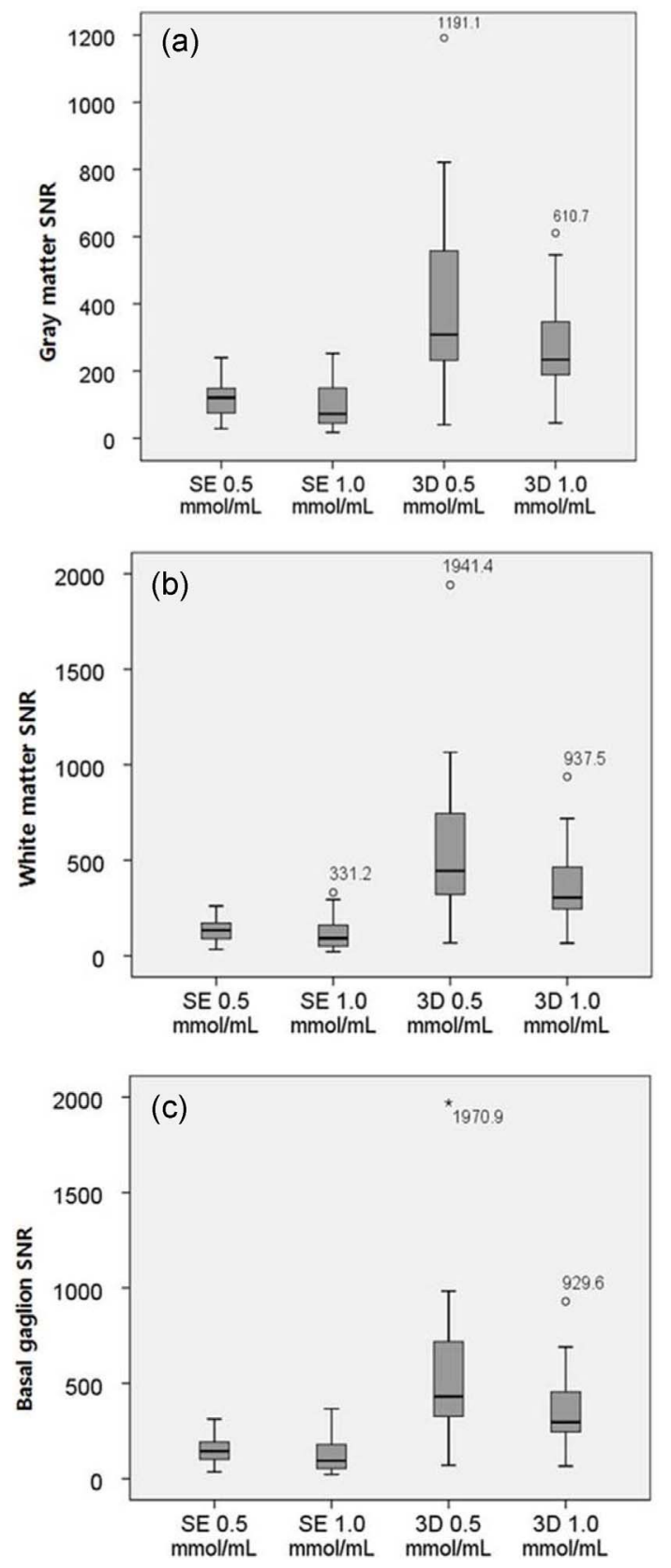

Fig. 4. The results for the measured SNR according to pulse sequences and contrast agent contents in (a) gray matter, (b) white matter, and (c) basal ganglion.

and $150.5 \pm 62.4$, respectively. The measured CNR using $0.5 \mathrm{mmol} / \mathrm{mL}$ gadoterate meglumine between white matter and basal ganglion was $15.2 \pm 12.7$ and the measured CNR between gray matter and basal ganglion was 34.7 \pm 17.4. Also, the measured SNR using $1.0 \mathrm{mmol} / \mathrm{mL}$ gadobutrol of white matter, gray matter, and basal ganglion was $98.1 \pm 66.1,118.9 \pm 83.6$, and $132.7 \pm 95.1$, respectively. The measured CNR using $1.0 \mathrm{mmol} / \mathrm{mL}$ gadobutrol between white matter and basal ganglion was $13.7 \pm 14.2$ 

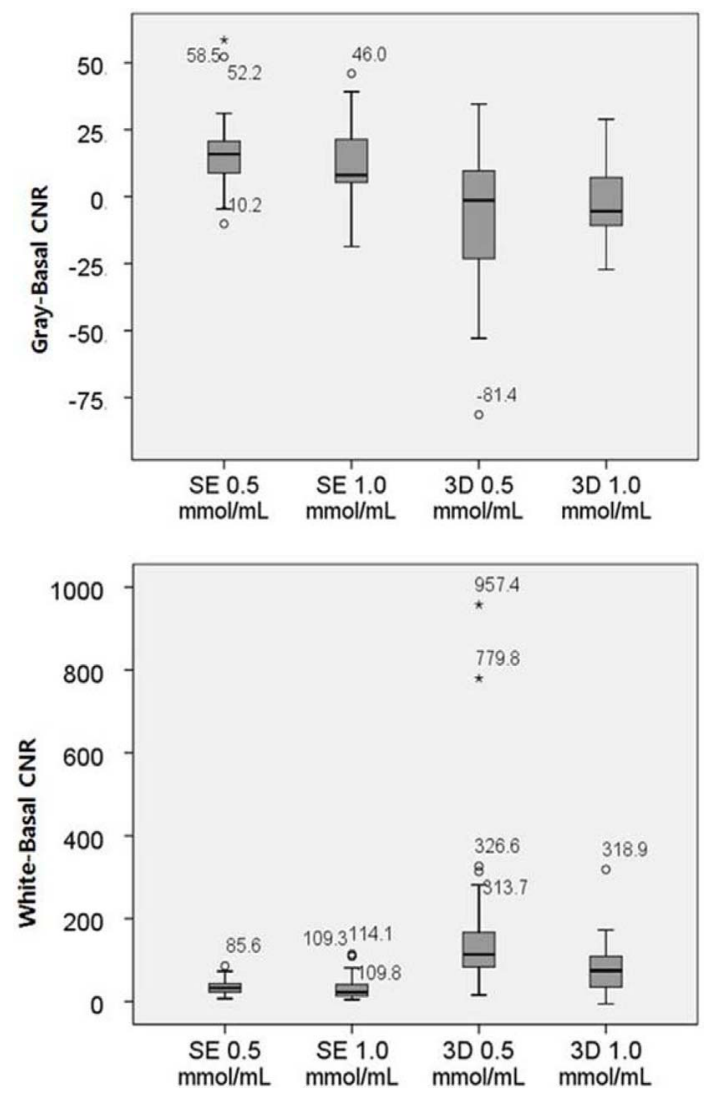

Fig. 5. The results for the measured CNR according to pulse sequences and contrast agent contents in (a) between gray matter and basal ganglion and (b) between white matter and basal ganglion.

and the measured CNR between gray matter and basal ganglion was $34.5 \pm 31.7$. According to the results, the measured SNR using $1.0 \mathrm{mmol} / \mathrm{mL}$ gadobutrol of white matter, gray matter, and basal ganglion was 12.1, 11.9, and $15.3 \%$ lower than that of $0.5 \mathrm{mmol} / \mathrm{mL}$ gadoterate meglumine, respectively. Also, the measured CNR using $1.0 \mathrm{mmol} / \mathrm{mL}$ gadobutrol of white matter and gray matter was 0.6 and $9.8 \%$ lower than that of $0.5 \mathrm{mmol} / \mathrm{mL}$ gadoterate meglumine, respectively.

Table 3 shows the results of independent samples of Ttest with SE pulse sequence. According to the results, the measured SNR using $1.0 \mathrm{mmol} / \mathrm{mL}$ gadobutrol of white matter, gray matter, and basal ganglion was 17.8, 16.4, and 17.6 lower than that of $0.5 \mathrm{mmol} / \mathrm{mL}$ gadoterate meglumine, respectively. Also, the statistical significance of SNR is not have much practical significance $(\mathrm{P}>$ 0.05 ). The measured CNR using $1.0 \mathrm{mmol} / \mathrm{mL}$ gadobutrol of white matter and gray matter was 1.4 and 0.2 lower than that of $0.5 \mathrm{mmol} / \mathrm{mL}$ gadoterate meglumine, respectively. Also, the statistical significance of CNR is not has much practical significance $(\mathrm{P}>0.05)$.
Table 3. Independent samples T-test according to the amount of contrast agent in SE pulse sequence.

\begin{tabular}{ccccc}
\hline \hline \multirow{4}{*}{ SNR } & & $\begin{array}{c}\text { Mean } \\
\text { difference }\end{array}$ & $\begin{array}{c}\text { Error } \\
\text { difference }\end{array}$ & P-value \\
& White matter & 17.8 & -29.1 & 0.325 \\
& Gray matter & 16.4 & -16.6 & 0.204 \\
& Basal ganglion & 17.6 & -32.4 & 0.347 \\
\hline \multirow{2}{*}{ CNR } & White matter & 1.4 & -1.5 & 0.654 \\
& Gray matter & 0.2 & -14.3 & 0.974 \\
\hline
\end{tabular}

Table 4. Independent samples T-test according to the amount of contrast agent in 3D CE-FFE pulse sequence.

\begin{tabular}{ccccc}
\hline \hline \multirow{3}{*}{ SNR } & Mean & Error & P-value \\
& White matter & 251.8 & -355.1 & 0.018 \\
& Gray matter & 248.6 & -247.9 & 0.022 \\
& Basal ganglion & 168.6 & -357.3 & 0.019 \\
\hline \multirow{2}{*}{ CNR } & White matter & 3.2 & -11.5 & 0.527 \\
& Gray matter & 79.6 & -116.3 & 0.025 \\
\hline
\end{tabular}

In 3D CE-FFE pulse sequence, the measured SNR using $0.5 \mathrm{mmol} / \mathrm{mL}$ gadoterate meglumine of white matter, gray matter, and basal ganglion was $428.5 \pm 376.4,599.4 \pm$ 542.6 , and 592.5 \pm 542.6 , respectively. The measured CNR using $0.5 \mathrm{mmol} / \mathrm{mL}$ gadoterate meglumine between white matter and basal ganglion was $6.8 \pm 25.1$ and the measured CNR between gray matter and basal ganglion was $164.1 \pm 181.2$. Also, the measured SNR using 1.0 $\mathrm{mmol} / \mathrm{mL}$ gadobutrol of white matter, gray matter, and basal ganglion was $259.8 \pm 128.4,347.5 \pm 187.5$, and 343.9 \pm 185.2 , respectively. The measured CNR using $1.0 \mathrm{mmol} /$ $\mathrm{mL}$ gadobutrol between white matter and basal ganglion was 3.6 \pm 13.6 and the measured CNR between gray matter and basal ganglion was $84.3 \pm 64.8$. According to the results, the measured SNR using $1.0 \mathrm{mmol} / \mathrm{mL}$ gadobutrol of white matter, gray matter, and basal ganglion was $39.4,41.9$, and $39.4 \%$ lower than that of $0.5 \mathrm{mmol} /$ $\mathrm{mL}$ gadoterate meglumine, respectively. Also, the measured CNR using $1.0 \mathrm{mmol} / \mathrm{mL}$ gadobutrol of white matter and gray matter was 48.6 and $47.1 \%$ lower than that of 0.5 $\mathrm{mmol} / \mathrm{mL}$ gadoterate meglumine, respectively.

Table 4 shows the results of independent samples T-test with 3D CE-FFE pulse sequence. According to the results, the measured SNR using $1.0 \mathrm{mmol} / \mathrm{mL}$ gadobutrol of white matter, gray matter, and basal ganglion was 248.6, 251.8 , and 168.6 lower than that of $0.5 \mathrm{mmol} / \mathrm{mL}$ gadoterate meglumine, respectively. The statistical significance of SNR has much practical significance $(\mathrm{P}<0.05)$. Also, the statistical significance of CNR between gray matter 
and basal ganglion has much practical significance $(\mathrm{P}<$ $0.05)$.

\section{Conclusion}

We have presented comparison results for SNR and CNR with different contrast agents for each pulse sequence. Our results showed that the SNR and CNR result of $0.5 \mathrm{mmol} / \mathrm{mL}$ gadoterate meglumine and 3D CEFFE pulse sequence was higher than that of $1.0 \mathrm{mmol} / \mathrm{mL}$ gadobutrol and SE pulse sequence in brain MRI, respectively. We demonstrated that the signal intensity is unlikely to be proportionate according to the contrast agent contents because of signal loss due to non-uniformity of magnetic field.

\section{References}

[1] A. Lignelli and A. G. Khandji, Neurosurg. Clin. N. Am. 22, 15 (2011).

[2] C. P. Kellner and A. L. D'Ambrosio, Neurosurg. Clin. N. Am. 22, 53 (2011).

[3] K. Yokoi, N. Kamiya, H. Matsuguma, S. Machida, T. Hirose, K. Mori, and K. Tominaga, Chest 115, 714 (1999).

[4] T. C. Ryken, M. McDermott, P. D. Robinson, M. Ammirati, D. W. Andrews, A. L. Asher, S. H. Burri, C. S. Cobbs, L. E. Gaspar, D. Kondziolka, M. E. Linskey, J. S. Loeffler,
M. P. Mehta, T. Mikkelsen, J. J. Olson, N. A. Paleologos, R. A. Patchell, S. N. Kalkanis, and G. C. Giakos, J. Neurooncol. 96, 103 (2010).

[5] R. Soffietti, R. Ruda, and R. Mutani, J. Neurol. 249, 1357 (2002).

[6] A. A. Postma, P. A. M. Hofman, A. A. R. Stadler, R. J. van Oostenbrugge, M. P. M. Tijssen, and J. E. Wildberger, AJR 199, S26 (2012).

[7] P. C. Davis, P. A. Hudgins, S. B. Peterman, and J. C. Hoffman, AJNR 12, 293 (1991).

[8] M. Filippi, T. Yousry, C. Baratti, M. A. Horsfield, S. Mammi, C. Becker, R. Voltz, S. Spuler, A. Campi, M. F. Reiser, and G. Comi, Brain 119, 1349 (1996).

[9] T. Barrett, H. Kobayashi, M. Brechbiel, and P. L. Choyke, Eur. J. Radiol. 60, 353 (2006).

[10] U. I. Attenberger, V. M. Runge, C. B. Jackson, S. Baumann, K. Birkemeier, H. J. Michaely, S. O. Schoenberg, M. F. Reiser, and B. J. Wintersperger, Invest. Radiol. 44, 251 (2009).

[11] B.-D. Jo, Y.-J. Lee, D.-H. Kim, and H.-J. Kim, J. Kor. Phys. Soc. 65, 541 (2014).

[12] P. H. Kuo, E. Kanal, A. K. Abu-Alfa, and S. E. Cowper, Radiology 242, 647 (2007).

[13] J. Biswas, C. B. Nelson, V. M. Runge, B. J. Wintersperger, S. S. Baumann, C. B. Jackson, and T. Patel, Invest. Radiol. 40,792 (2005).

[14] K. J. Chang, I. R. Kamel, K. J. Macura, and D. A. Bluemke, RadioGraphics 28, 1983 (2008). 